\title{
تقدير بعض المعادن الثقيلة في أنواع من التوابل المتوفرة بالأسواق المحلية بمنطقة
}

\section{وادي الثاطي جنوب ليبيا}

\section{محمود عبد الله إمريمي1، ميلاد موسى عكاشة2، محمد عبدالله الثريف3}

3،2،1 قسم علوم وتقنية الأغذية - كلية العلوم الهندسية والتقنية - جامعة سبها

الملخص

في السنين الأخيرة ازداد الاهتمام بسلامة المنتجات الغذائية من الملوثات الضـارة ، ومن هذه الملوثات تلوث الأغذيـة بالمعـادن الثقيلـة ، وتعد التوابـل مـن المـواد التي تضـاف إلى الغذاء بغرض تحسين صفاته الحسية ، وقد تكون هذه التوابل بها بعض المعادن الضارة والبعض الآخر من المعادن إذا زاد تركيزها عن حدود معينة يسبب العديد من المشاكل الصحية للإنسان لهذا أجريت هذه الدراسـة على بعض عينات من التوابل التي تباع في الأسواق في منطقة وادي الثاطي بجنوب ليبيا بغرض معرفة تركيزها من بعض المعادن الثقيلة وشملت التوابل التالية (الزنجبيل ، الكركم ، الكرويـة ، الفلفل الأكحل ، حبة البركة ، الفلفل الأحمر ، الكمون ، القرفة ، الكسبر) وأوضحت الدراسة تباين في تركيز المعادن في عينات التوابل حيث كان أعلى تركيز للحديد سجل في عينـة الكرويـة 255 ملجم/كجم ، في حين كان التركيز الأعلى للزنك في عينة الكمون 78 ملجم/كجم ، أما الكادميوم فكان أعلى تركيز في عينة الكمون 3.2 ملجم/كجم ، بينما سجل أعلى تركيز للرصاص في عينة الكسبر 32 ملجم/كجم ، وكان أعلى تركيز للمنجنيز سجل في عينة الكسبر 76 ملجم/كجم ، وهناك بعض العينات تجاوزت الحـد الأقصـى المسـموح بهـا طبقـاً للمواصـفات القياسـية لمنظمــة الصـحة العالميـة ومنظمـة الأغذيـة والزراعة. الكلمات المفتاحية: التوابل، المعادن الثقيلة، المواصفات القياسية، تلوث الأغذية. 
تعرف التوابل بأنها الأجزاء المجففة من بذور وجذور وأوراق وثمار النباتات العطرية ، والتي تضاف إلى الأغذية بغرض تحسين طعم أو نكهة أو رائحسة أو لون الأغذية ، أو هي الأجزاء العطريـة من النباتات التي تستخدم لإضـافة نكهات للغذاء (Hinneburg, et al., 2006) ، تزرع التوابل في مناطق مختلفة من العالم وتضاف منذُ القدم إلى الأطعمة والوجبات الغذائية بغرض تحسين صفاتها الحسية بإضفاء النكهات المرغوبة إليها، وذلك لاحتواها على مركبات الحيوية النشطة التي تعمل على التى تحسين طعم الأغذية بالإضافة إلى تأثيرها على عمليات الهضم وعمليات الأيض ، وهي تحتوي أيضاً على بعض المعادن الضرورية لعمليات الأيض الحيوية التي تتم في جسم الإنسان ويحتاجها بكميات صغيرة مثل النحاس والزنك والحديد والمنجنيز والكوبالت ، وبالرغم من الفوائد العديدة التي تقدمها

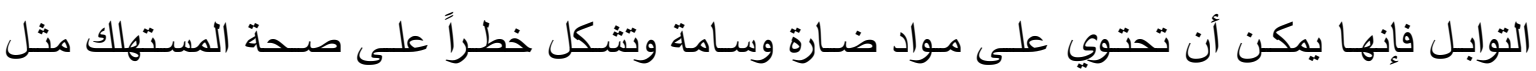
الرصاص والزئبق والكادميوم وبقايا المركبات الهيدروكربونية الحلقية والمبيدات الحشرية ، والتي يمكن

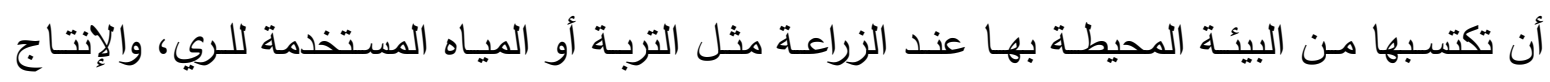
والتصنيع والتداول والتخزين. Fergusson , 1990., Ozcan, 2004., Divrikli et al., نردئ 2006 Krejpcio et al., 2007; Abdullahi et al., 2008 Gulzar et al. , 2012) أجريت هذه الدراسة بغرض معرفة تركيز بعض المعادن الثثيلة في أنواع مختلفة من التوابل التي تباع في الأسواق المحلية بمنطقة وادي الثاطي بجنوب ليبيا

المواد والطرق

أولاً المواد

شملت الدراسة منطقة وادي الثاطي حيث جُمعت عينات التوابل (مساحيق) لعلامات تجارية مختلفة وهي الزنجبيل والكركم والفلفل الأكحل والكسبر وحبة البركة والقرفة والفلفل الأحمر والكمون والكرويـة من الأسواق التجارية. 
أجري ترميد رطب لعينات التوابل بوزن واحد جرام من كل صنف من التوابل ثم أضيف لها حمض الكبريتك والنتريك وفوق أوكسيد الهيدروجين ثم الترشيح بورق ترشيح عديم الرماد وأستقبال الراشح في

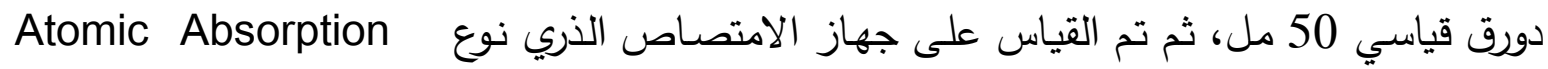
. Perkin Elmer 2380 Spectrophotometer الجدول (1): يوضح الأسم الثائع والأسم العلمي والجزء المستخدم من التوابل.

\begin{tabular}{|c|c|c|}
\hline الجزء المستخدم من التوابل & الأسم العلمي & الأسم الثائع \\
\hline الثمار & Capsicum Frutescens & الفلفل الأحمر \\
\hline البذور & Cuminum cyminum & 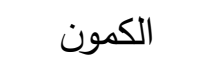 \\
\hline البذور & Nigell sativa & حبة البركة \\
\hline اللحاء، قشور الثجرة & Cinnamomum verum & 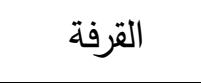 \\
\hline الجذور & Cuccuma longa & 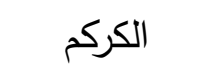 \\
\hline البذور & Capsicum nigrum & فلفل الأكحل \\
\hline الجذور & Zingiber afficenalis & الزنجبيل \\
\hline البذور & Carum carvi & الكروية \\
\hline الثمار & Coriandrum sativum & الكسبر \\
\hline
\end{tabular}

\section{النتائج والمناقثة}

نتائج هذه الدراسة المبوبة بالجدول (2) أوضحت أن تركيز لحديد في العينات المدروسة كان ضمن الحدود المسموح بها من قبل منظمـة الصحة العالمية ومنظمـة الأغذيـة والزراعـة حيث كانت عينـة الكروية هي الأعلى تركيزاً بالحديد 255 ملجم/كجم بينما كان أقل تركيز قد سجل في عينة الكمون الحلو وكان دون حدود الكثف في حين كان تركيز الحديد في باقي العينات كالتالي: حبة البركة 80.2 ملجم/كجم، الفلفل الأكل 68 ملجم/كجم، الكركم 42.5 ملجم/كجم، الفلفل الأحمر 42.4 
Darko et.al , ملجم/كجم، القرفة والزنجبيل 4.3 ملجم/كجم. وتتقارب هذه النتائج مع ما ذكره 2014) ولا تتوافق مع نتائج (Olnsakin and Olaouwa , 2016)، نتائج التحليل الإحصائي دلت على عدم وجود أي ارتباط معنوي للحديد.

المنجنيز

وجد أن تركيز المنجنيز في عينات التوابل المدروسة والمبينة بالجدول (2) قد تراوحت ما بين دون حدود الكثف وكان في عينة الفلفل الأكحل وهي أقل تركيز و76 ملجم/كجم التي كانت في عينـة الكسبر وهي الأعلى تركيزاً ،أمـا تراكيز هذا العنصر في باقي العينات فكانت: الفلفل الأحمر 64 ملجم/كجم، الزنجبيل 45 ملجم/كجم، الكروية والقرفة 29 ملجم/كجم، الكمون الحلو 22.3 ملجم/كجم، الكركم 19.3 ملجم/كجم وحبة البركة 19 ملجم/كجم، ولم يتسن الحصول على دراسات للمقارنة بها، وأشارت نتائج التحليل الإحصائي على عدم وجود أي ارتباط معنوي للمنجنيز .

من خلال النتائج الموضحة بالجدول (2) تبين أن جميع العينات كانت ضمن الحد الأقصى المسموح به نقبل منظمة الصحة العالمية ومنظمة الأغذية والزراعة وكان أعلى تركيز للزنك في عينات التوابل في عينة الكمون الحلو 78 ملجم/كجم بينما كان دون حدود الكثف في عينة الفلفل الأكحل، وكان تركيز الزنكك في باقي العينات: القرفة 68 ملجم/كجم ،حبة البركة 67.3 ملجم /كجم، الفلفل الأحمر

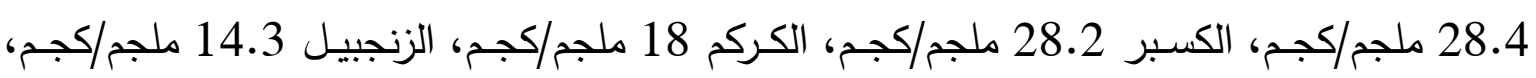
والكروية 4.0 ملجم/كجم. وتتوافق هذه نتائج مع دراسات أخرى مثل ( Darko et.al , 2014 )، ومن خلال التحليل الإحصائي لنتائج عينات التوابل تبين عدم وجود ارتباط معنوي للزنك.

الكادميوم

أشارت النتائج المتحصل عليها لعينات التوابل المدروسة والمبينة بالجدول (2) أن أقل تركيز للكادميوم قد سجل في كل من الفلفل الأحمـر وحبـة البركـة والفلفل الأكحل والكرويـة حيث كـان دون حدود الكثف وهي تقع ضمن الحد الأقصى المسموح به من قبل منظمة الصحة العالمية، أما أعلى تركيز فكان في عينة الكمون الحلو 3.2 ملجم/كجم، وكان تركيز الكادميوم في باقي العينات كالتالي: في القرفة 2.1 ملجم/كجم، الزنجبيل 1.9 ملجم/كجم، الكسبر 0.8 ملجم/كجم، الكركم 0.4 ملجم/كجم 
.وهذه العينات قد تجاوزت الحد الأقصى المسموح به من قبل منظمة الصحة العالمية ومنظمة الأغذية. (Ziyaina et al., 2014) والزراعة وهذه النتائج تتوافق مع نتائج أخرى يتجاوز الحدود المسموح بهان و ( Darko et.al , 2014 )و (Olnsakin and Olaouwa , 2016)،وأوضح التحليل الإحصائي للعينات الددروسة عدم وجود ارتباط معنوي للكادميوم.

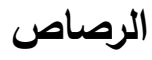

دلت النتائج لعينات التوابل المدروسة والمبينة بالجدول (2) على وجود تراكيز مرتفعة من الرصاص في بعض العينات التي تجاوزت الحد الأقصى المسموح به من قبل منظمة الصحة العالمية ومنظمة الأغذية والزراعـة، حيث كان أعلى تركيز قد سجل في عينـة الكسبر 32 ملجم/كجم ثم القرفة 16 ملجم/كجم والكمون الحلو 16 ملجم/كجم والكركم 8 ملجم/كجم في حين كان تركيز الرصـاص دون حدود الكثف في عينات الفلفل الأحمر وحبة البركة والزنجبيل والفلفل الأكحل والكرويـة .إن هذه النتائج قد تجاوزت الحدود المسموح بها في المواصفات (Ziyaina et . al 2014) و ( Darko (et.al , 2014 للرصاص عدم وجود ارتباط معنوي.

الجدول (2): يوضح تركيز المعادن الثقيلة بملجم/كجم في عينات التوابل.

\begin{tabular}{|c|c|c|c|c|c|}
\hline الرصاص & الكادميوم & الزنك & المنجنيز & الحديد & أسم التوابل \\
\hline 32 & 0.8 & 28.2 & 76 & ND & الكسبر \\
\hline 8.0 & 0.4 & 18 & 19.3 & 42.5 & الكركم \\
\hline ND & ND & 28.4 & 64 & 4.42 & الفلفل الأحمر \\
\hline ND & ND & 67.3 & 19 & 80.2 & حبة البركة \\
\hline ND & 1.9 & 3.14 & 45 & 3.4 & الزنجبيل \\
\hline ND & ND & ND & ND & 68 & فلفل الأكحل \\
\hline 16 & 2.1 & 68 & 29 & 3.4 & القرفة \\
\hline 16 & 3.2 & 78 & 22.3 & ND & كمون الحلو \\
\hline ND & ND & 4.0 & 29 & 255 & الكروية \\
\hline 10 & 0.3 & 100 & & 300 & WHO/FAO \\
\hline
\end{tabular}

ND 
الجدول (3): يوضح التحليل الإحصائي للمعادن الثقيلة لعينات التوابل المدروسة.

\begin{tabular}{|c|c|c|c|c|c|}
\hline & $\mathbf{P b}$ & $\mathbf{F e}$ & $\mathbf{M n}$ & $\mathbf{C d}$ & $\mathbf{Z n}$ \\
\hline $\mathbf{P b}$ & 1 & -0.288 & 0.452 & 0.433 & 0.349 \\
\hline $\mathbf{F e}$ & -0.288 & 1 & -0.092 & -0.323 & -0.388 \\
\hline $\mathbf{M n}$ & 0.452 & -0.092 & 1 & 0.013 & -0.048 \\
\hline $\mathbf{C d}$ & 0.433 & -0.323 & 0.013 & 1 & 0.585 \\
\hline $\mathbf{Z n}$ & 0.349 & -0.388 & -0.048 & 0.585 & 1 \\
\hline
\end{tabular}

\section{التوصيات}

1- إصدار مواصفة قياسية محلية خاصة بالتوابل حتى يتم الاسترشاد بها في تقييم جودتها.

2- تثديد الرقابة على التوابل الموردة ومنع الاستيراد من الدول التي تتواجد بشحناتها كميات تتجاوز الحدود المسموح بها من المعادن الثقيلة.

3- الاهتمام بدراسة التوابل وما تحتويه من مواد ضارة وذلك لكثرة استخدامها في الأغذية وما قد تسببه هذه المواد الضارة من أمراض للمستهلكين.

- Abdullahi, M.S., Uzairu, A. and Okunola, O.J. 2008. Determination of some trace metal levels in onion leaves from irrigated farmlands on the bank of River Challawa Nigeria. African Journal Biotechnol. (7) 10 :1526-1529.

- Darko, B., Ayim, I., and Voegborlo, R. 2014. Heavy metal content in mixed and unmixed seasonings on the Ghanaian market. African Journal of Food Science, 8 (1) : $14-19$.

- Divrikli, U.,Horzum, N., Soylak, M. and Elci, L. 2006. Trace heavy metal contents of somespices and herbal plants from western Anatolia Turkey. International Journal Food Science Technology, (41) : 712-716.

- Fergusson, J.E .1990. The Heavy elements Chemistry, Environmental Impact and HealthEffects. Eds. Pergamin Press, Oxford.Pp 382-399. 
- Gulzar, I., Lutfia, M., Shirwan, O. and Sirwan, S. 2012.Effect ofHeavy Metal Content of some Common Spices Available in Local Markets in Erbil City on Human Consumption, Raf. Journal Science, 23 (3) : 106-114.

- Hinneburg, I., Damien-Dorman, H.J. and Hiltunen, R .2006 . Antioxidant activities of extractsfrom selected culinary herbs and spices. Food Chemistry, $97: 122-129$.

- Krejpcio, Z., Król , E. and Sionkowski, S. 2007. Evaluation of Heavy Metals Contents in Spices and Herbs Available on the Polish Market. Polish Journal of Environmental Studies, 16 ( 1) : 97 - 100.

- Olnsakin, P., and Olaouwa, J. 2016. Evaluation of Effects of Heavy Metal Contents of Some Common Spices Available in Odo- Ori Market Iwo Nigeria. Journal of Environmental Analytical Chemistry, 3 (1).

- Ozcan M. 2004.Mineral contents of some plants used as condimentsin Turkey. Food Chemistry, 84, 437.

- WHO. 1989. Evaluation of certain food additives and contaminants. WHO Technical Report Series 776. Geneva: World Health Organization.

- Ziyaina, M., Rajab, A., Alkhweldi, K., Algami, W., Al-Toumi, O and Rasco, B .2014. Lead and cadmium residue determination in spices available in Tripoli City markets Libya. African Journal of Biochemistry Research, 8(7) : 137- 140. 